\title{
Differences in web features between two sympatric Leucauge species (Araneae: Tetragnathidae) suggest a trade-off in prey capture strategy
}

\author{
Alejandra Vargas-Gamboa ${ }^{1}$ and Gilbert Barrantes ${ }^{1,2}:{ }^{1}$ Escuela de Biología, Universidad de Costa Rica, Ciudad \\ Universitaria Rodrigo Facio, 2060 San José, Costa Rica; ${ }^{2}$ Centro de Investigación en Biodiversidad y Ecología Tropical \\ (Cibet), Universidad de Costa Rica, Ciudad Universitaria Rodrigo Facio, 2060 San José, Costa Rica; E-mail: gilbert. \\ barrantes@gmail.com
}

\begin{abstract}
The design of orb webs is affected by multiple abiotic (e.g., wind, available space), biotic (e.g., prey availability, predation), and species specific (e.g., spider size) factors. Thus, some features of each spider web are expected to reflect the combined effect of such factors. We compared the relationship of spider size and web inclination on the area of different sections of the orb web and other features (e.g., number or radii) between two sympatric Leucauge species (Leucauge sp., and L. argyra (Walckenaer, 1841), Tetragnathidae). Leucauge sp. was smaller and constructed smaller webs across a wider range of inclinations than L. argyra. Other features of the web, e.g., capture area, and hub area, but not the number of adhesive spiral turns and number of radii, were also larger in webs of L. argyra. The inclination was greater in webs of Leucauge sp., but the asymmetry of webs did not differ between species, though, it correlated negatively with the total area of the web of both species, as in other orb-weavers. The characteristics of each species' web suggest that $L$. argyra optimizes prey interception, while Leucauge sp. optimizes stopping and retention of large prey.
\end{abstract}

Keywords: Orb webs, spider size, web asymmetry, web inclination.

https://doi.org/10.1636/JoA-S-19-063

The capacity of animals to adjust their behavior in response to either temporal environmental fluctuation or spatial variations of the same environment is expressed in a wide range of vertebrate and invertebrate taxa (West-Eberhard 2003; Blamires et al. 2007). Plastic behavioral responses are in general difficult to quantify, but some behavioral patterns and construction rules could be identified from structures that animals built (extended phenotypes) (Collias \& Collias 1984; Vollrath 1998; Hansell 2005; Boutry \& Blamires 2013). For instance, spider orb-webs are structures whose design depicts the complexity and variation of the spider behaviors and their morphology (Vollrath 1992; Heiling \& Herberstein 1998, 2000; Eberhard \& Barrantes 2015).

In nature, spiders are capable of constructing their webs in spaces that vary widely in dimensions and shape (Witt 1965), suggesting a flexible response of orb-weavers to variation in the environment. This spider's flexibility could be attributed to multiple causes (Ades 1995; Barrantes \& Eberhard 2012), but in nature the size and shape of the space available, the number and spatial distribution of anchoring sites, as well as the distribution of different prey types are likely important variables affecting the size, shape, and inclination of orb webs (Herberstein \& Heiling 1999; Heiling \& Herberstein 2000; Blamires et al. 2007; Gregorič et al. 2013; Tew \& Hesselberg 2018).

Webs fulfil several functions for the spiders (e.g., retreat, protection, reproduction), but their main function is prey capture (Eberhard 1990; Herberstein \& Tso 2011). Therefore, adjustments the spiders make on their webs are expected to maintain or even increase the efficacy of intercepting, stopping, and retaining prey (Sandoval 1994). The orb web has a conservative design across different spider families (Eberhard 1990; Vollrath 1998). It consists of a frame and radii that give support to the hub and the adhesive spiral that constitutes the capture area. The hub, made of dry silk threads, is the functional center of an orb web and serves the spider as a launch platform from which the spider is able to sense prey position through vibrations transmitted by the radii (Briceño \& Eberhard 2011). Two additional sections, the free zone that is the section of the web enclosed between the outer turn of the hub and the inner turn of the adhesive spiral, and an empty zone between the outer adhesive spiral turn and the frame threads are present in webs of many orb-weavers (Fig. 1a).

When orb-web spiders are experimentally confined to reduced spaces (compared with field webs), they either construct extremely modified webs - and many such changes are apparently aimed to optimize the web main functions (Barrantes \& Eberhard 2012; Eberhard \& Barrantes 2015) - or construct miniature but non-modified webs (Hesselberg 2013). Leucauge argyra (Walckenaer, 1841) (Tetragnathidae) and Zosis geniculata (Olivier, 1789) (Uloboridae) confined to reduced spaces modify several aspects of the web to maintain its functionality. They construct webs without frames or empty zones, with denser adhesive spiral turns, and radii that attach directly to the substrate, allowing spiders to construct a relatively large capture area (Eberhard 2014). However, the hub changes little relative to the total available space, because for this area to be functional as a launching platform and information center, it should have a minimal area, which correlates with the spider size (Briceño \& Eberhard 2011; Barrantes \& Eberhard 2012; Eberhard \& Barrantes 2015).

The total area, inclination, and asymmetry of the webs depend on the available space and the position of anchoring points within the microhabitat the spider chooses to construct its web, and also on the spider size (Janetos 1986; Blamires et al. 2007; Nakata \& Zschokke 2010; Tew \& Hesselberg 2018). It has been demonstrated that the total area of an orb-web correlates positively with the area of other sections of the orb (e.g., capture area, hub area), as well as with the number of 

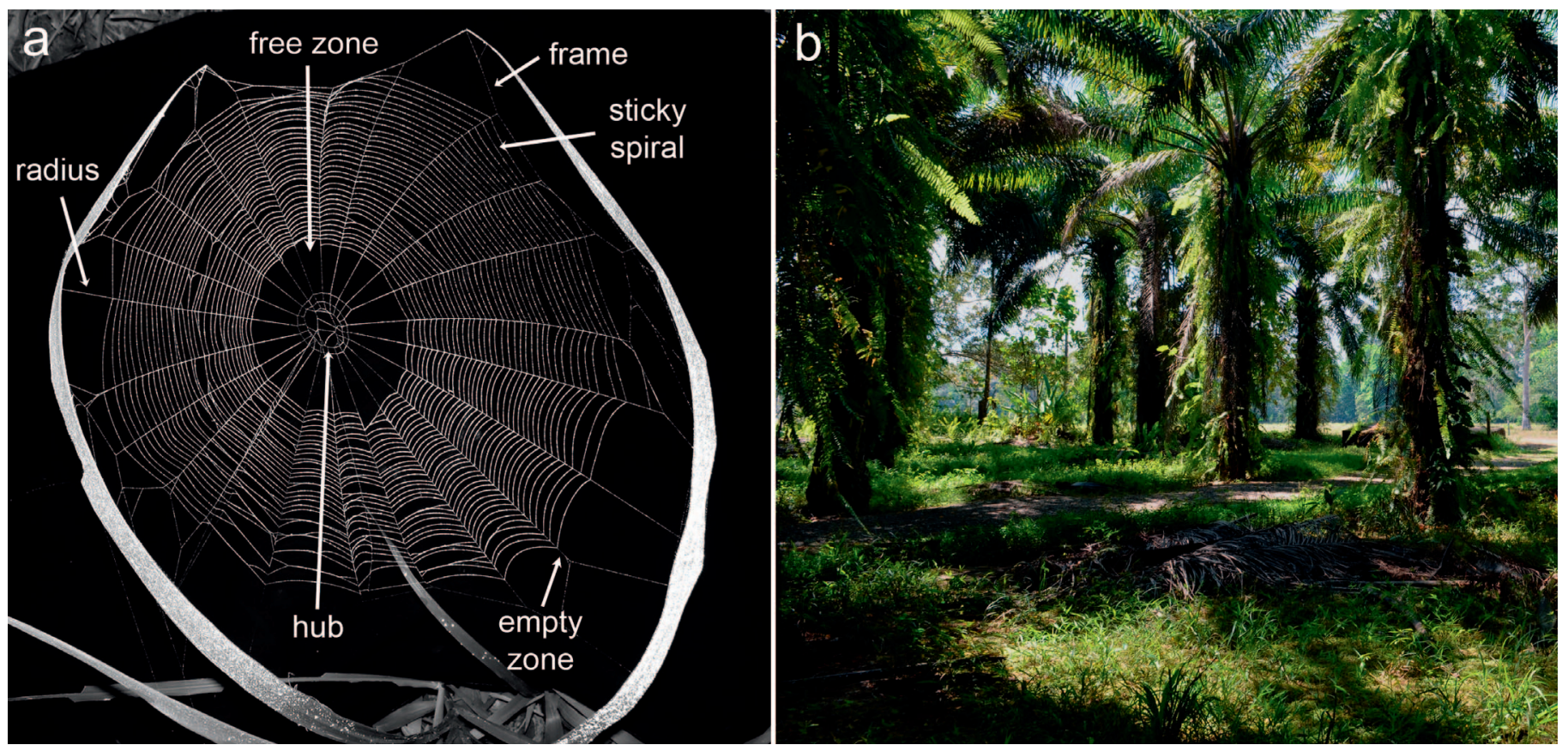

Figure 1.-Web of Leucauge argyra (a) and microhabitat used by both Leucage species (b).

radii and spiral turns (Barrantes \& Eberhard 2012; Eberhard $\&$ Barrantes 2015). But both total area and inclination often correlate negatively with web asymmetry (Nakata \& Zschokke 2010; Tew \& Hesselberg 2018). Here we test if two sympatric Leucauge species (Lencauge argyra and Leucauge sp.) that differ in size but use the same microhabitat, construct webs with different design: inclination, asymmetry, area of different section of the web, number of radii, and number of spiral turns. Specifically, we predict a greater web asymmetry for larger spiders with higher inclination, within and between species. It has been demonstrated that in some species large spiders construct more asymmetric webs, presumably because the slower upward running of the spider could affect prey capture at the upper section of the web (Hesselberg 2010; Nakata 2010; Nakata \& Zschokke 2010). We also expect greater adjustments of web features for smaller webs, as was found when spiders were confined to reduced spaces in lab conditions (Barrantes \& Eberhard 2012; Eberhard \& Barrantes 2015).

\section{METHODS}

Focal species.- In Costa Rica, both Leucauge species occur from sea level to about $500 \mathrm{~m}$ a.s.1. and construct their webs at forest edges and understory of plantations on herbaceous and bushy vegetation from 0.20 to $1.50 \mathrm{~m}$ above the ground (Aisenberg \& Barrantes 2011; Barrantes et al. 2015). Leucauge argyra is larger than Leucauge sp. but both species often construct their webs side by side on the same type of vegetation at the same height (Fig. 1b). Both species were common at the study site, but Leucauge sp. was more abundant (in a $300 \times 4 \mathrm{~m}$ transect, we counted 26 L. argyra and 178 Leucauge sp.). To avoid misidentifications, specimens of both species were compared with those previously collected in the same area and deposited in the spider collection in the Museo de Zoología, Universidad de Costa Rica.

Data collection.-We conducted this research in an African oil palm plantation (Elaeis guineensis) in Rincón de Osa, Puntarenas province, Costa Rica $\left(8^{\circ} 41^{\prime} \mathrm{N}, 83^{\circ} 29^{\prime} \mathrm{W}\right.$; elevation $45 \mathrm{~m}$ ) from January 26 to February 6, 2017; this period coincides with the breeding peak of both species at the study site (GB unpubl. data). The annual mean temperature is $26^{\circ} \mathrm{C}$ and precipitation is $4247 \mathrm{~mm}$ in the region (Solano \& Villalobos 2001), with a dry period from December through March. This plantation consists of palms planted every $15 \mathrm{~m}$, and a relatively dense herbaceous stratum (e.g., Carludovica sp., Selaginella sp., ferns, and grasses) (Fig. 1b). This herbaceous stratum and piled palm leaves that are trimmed as part of the plantation maintenance, provide the substrates for spiders to anchor their webs.

We collected web information from adult females only for both species, L. argyra $(n=23)$ and Leucauge sp. $(n=50)$. We selected intact webs of adult females constructed between 50 and $150 \mathrm{~cm}$ above the ground and recorded the position of the spider in the web to determine the superior and inferior section of the web. Spiders position themselves in their webs head down, so we used the position of the spider to define the sections of the web. We measured the angle of the web with $0^{\circ}$ being horizontal and $90^{\circ}$ being vertical, using a clinometer (Brunton, Omni-Slope). We then coated the web with talcum powder, placed a ruler $( \pm 0.05 \mathrm{~mm})$ gently besides the web plane and photographed (digital camera Nikon D5100) each of the webs. We took special care to always place the camera lens perpendicular to the plane of the web. These Leucauge species are known to construct several webs daily (W. Eberhard \& G. Barrantes unpubl. data), even if webs are apparently undamaged, and the first web is constructed early in the morning. Thus, to avoid variation between webs of the same spider, we photographed only the first web constructed. 
After photographing the web, we preserved each spider with $80 \%$ ethanol, and measured the cephalothorax width as a proxy of its size under a dissecting microscope (Nikon SMZ645). Cephalothorax width has recurrently been used as a proxy of body size in spiders (Eberhard 1988; Barrantes 2015). To define the superior and inferior sections of the web, we first traced a line along the longitudinal axis of the spider, when the spider was first observed on the web, then a perpendicular line across the center of the hub to define the superior and inferior sections of the web.

From the photograph of each web, we measured the following variables: number of spiral turns above (superior section of the web) and below the hub (inferior section of the web); total number of radii, total area (area circumscribed within the outer spiral turn), hub area, free zone area, and capture area as in Barrantes \& Eberhard (2012). The spiral turns were counted along the radius closest to the line that defined the longitudinal axis of the spider (above and below the hub) and calculated the mean of the counts above and below the hub. We used the program Image $\mathbf{J}$ (Rasband 2016) to measure the area of the different sections of the web and calculated the asymmetry of the orb web using the formula proposed by Zschokke (2011): [(HA-HB)/(HA+HB)]; where $\mathrm{HA}$ is the distance from the hub to the outermost spiral turn above the hub, and $\mathrm{HB}$ the distance from the hub to the outermost spiral turn below the hub.

Statistical analyses. - We compared a group of web features (see previous section and Tables 1,2) between the two Leucauge species, using General Linear Models (GLMs; library nlme, R language) with a Gaussian error distribution. We evaluated the assumptions of homoscedasticity and normal distribution of residual for all models. In the first two models, we compared cephalothorax width and total area between the two species (Table 1). In consecutive models, we additionally included cephalothorax width, web inclination, and two interactions (cephalothorax width*species, and species*web inclination) as predictor variables (Table 1). These full models allowed us to test the relationships between the predictors and those web features described in the previous section (Table 1) that are expected to experience some change as the size of the spider and web inclination change (Hesselberg 2013; Tew \& Hesselberg 2018). We performed two other models to compare (1) web asymmetry, and (2) web inclination between the two spider species. In the first case we included total web area, cephalothorax width, and web inclination as predictor variables; and total web area and cephalothorax width in the second case (Table 2), as these variables are known to correlate with each of the corresponding response variables. In all cases, we started with the full model and then selected the model that best explained the variation of the response variable, based on AIC (Akaike Information Criterion) (Wagenmakers \& Farrell 2004), and statistical differences between the two models with the lowest AIC values (Zuur et al. 2012).

\section{RESULTS}

The cephalothorax width (spider size) of Leucauge argyra was larger $(2.17 \mathrm{~mm} \pm 0.05 \mathrm{SE}, P<0.001)$ than that of Leucauge sp. (1.37 mm $\pm 0.06 \mathrm{SE}$; Table 1; Fig. 2a). Accordingly, L. argyra constructed larger webs (total area:
Table 1.-Difference in spider size and total area between Leucauge argyra and Leucauge sp. (L. sp.); and relationships between spider size and web inclination on different web features of both species.

\begin{tabular}{lccccc}
\hline \multicolumn{6}{c}{ Response variable: cephalothorax width (spider size) } \\
\hline \multicolumn{1}{c}{ Effect } & Coefficient & SE & T & df & P \\
\hline L. argyra & 2.17 & 0.05 & 41.91 & 72 & $<0.001$ \\
Leucauge sp. & -0.81 & 0.06 & -12.88 & 72 & $<0.001$
\end{tabular}

\begin{tabular}{lcccccc}
\multicolumn{8}{c}{ Response variable: Total area } \\
\hline L. argyra & 574.80 & 28.21 & 20.37 & 72 & $<0.001$
\end{tabular}

$\begin{array}{llllll}\text { L. sp. } & -266.72 & 34.09 & -7.82 & 72 & <0.001\end{array}$

Response variable: Total area

\begin{tabular}{lrrrrr}
\hline L. argyra & 323.87 & 163.02 & 1.99 & 61 & 0.052 \\
L. sp. & -154.14 & 71.16 & -2.17 & 61 & 0.034 \\
Cph. width & 122.12 & 71.66 & 1.70 & 61 & 0.094 \\
Inclination & -0.70 & 1.41 & -0.50 & 61 & 0.622
\end{tabular}

\begin{tabular}{|c|c|c|c|c|c|}
\hline \multicolumn{6}{|c|}{ Response variable: Capture area } \\
\hline L. argyra & 310.28 & 159.48 & 1.95 & 61 & 0.057 \\
\hline L. sp. & -144.27 & 69.61 & -2.07 & 61 & 0.042 \\
\hline Cph. width & 114.11 & 70.10 & 1.63 & 61 & 0.109 \\
\hline Inclination & -0.71 & 1.38 & -0.51 & 61 & 0.609 \\
\hline \multicolumn{6}{|c|}{ Response variable: Free zone area } \\
\hline L. argyra & 11.00 & 5.75 & 1.91 & 61 & 0.061 \\
\hline L. sp. & -8.08 & 2.51 & -3.22 & 61 & 0.002 \\
\hline Cph. width & 8.02 & 2.53 & 3.17 & 61 & 0.002 \\
\hline Inclination & 0.01 & 0.05 & 0.15 & 61 & 0.885 \\
\hline \multicolumn{6}{|c|}{ Response variable: Hub area } \\
\hline L. argyra & 3.92 & 1.11 & 3.55 & 61 & 0.001 \\
\hline L. sp. & -4.38 & 1.40 & -3.14 & 61 & 0.003 \\
\hline Cph. width & -0.70 & 0.48 & -1.45 & 61 & 0.153 \\
\hline Inclination & 0.01 & 0.01 & 0.92 & 61 & 0.359 \\
\hline L. sp. ${ }^{*}$ Cph. width & 1.69 & 0.75 & 2.27 & 61 & 0.027 \\
\hline L. sp.*Inclination & -0.01 & 0.02 & -0.72 & 61 & 0.474 \\
\hline \multicolumn{6}{|c|}{ Response variable: Number of radii } \\
\hline L. argyra & 20.84 & 4.66 & 4.47 & 72 & $<0.001$ \\
\hline L. sp. & 10.53 & 5.52 & 1.91 & 72 & 0.061 \\
\hline Cph. width & 4.51 & 2.10 & 2.15 & 72 & 0.035 \\
\hline Inclination & -0.01 & 0.02 & -0.26 & 72 & 0.794 \\
\hline L. sp. ${ }^{*}$ Cph. width & -7.52 & 3.03 & -2.48 & 72 & 0.015 \\
\hline \multicolumn{6}{|c|}{ Response variable: Mean spiral turns } \\
\hline L. argyra & 50.25 & 7.27 & 6.91 & 72 & $<0.001$ \\
\hline L. sp. & -5.44 & 3.29 & -1.65 & 72 & 0.103 \\
\hline Cph. width & -3.34 & 3.24 & -1.03 & 72 & 0.306 \\
\hline Inclination & 0.03 & 0.053 & 0.56 & 72 & 0.578 \\
\hline
\end{tabular}

$\left.574.80 \mathrm{~cm}^{2} \pm 28.21 \mathrm{SE}\right)$ than Leucauge sp. $\left(308.08 \mathrm{~cm}^{2} \pm\right.$ 34.09 SE; Table 1; Fig. 2b). The capture area, free zone area, and hub area were also larger in webs of L. argyra than in those of Leucauge sp. (Table 1).

The size of spiders correlated with some web features but not with others. The free zone increased with body size in both species (Cph. Width in Free zone, Table 1), and the hub area increased with body size only in Leucauge sp. (L. sp. ${ }^{*} \mathrm{Cph}$. Width, in Hub area, Table 1). However, the number of radii 
Table 2.- Relationships between total area and spider size with asymmetry and inclination in webs of Leucauge argyra and Leucauge sp. (L. sp.).

\begin{tabular}{|c|c|c|c|c|c|}
\hline \multicolumn{6}{|c|}{ Response variable: asymmetry } \\
\hline Effect & Coefficient & $\mathrm{SE}$ & $\mathrm{T}$ & df & $\mathrm{P}$ \\
\hline L. argyra & -0.05 & 0.10 & -0.59 & 72 & 0.590 \\
\hline L. sp. & -0.01 & 0.04 & -0.34 & 72 & 0.735 \\
\hline Total area & -0.00 & 0.00 & -2.52 & 72 & 0.014 \\
\hline Inclination & -0.00 & 0.00 & -0.29 & 72 & 0.769 \\
\hline Cph. width & 0.02 & 0.04 & 0.62 & 72 & 0.534 \\
\hline \multicolumn{6}{|c|}{ Response variable: inclination } \\
\hline Effect & Coefficient & $\mathrm{SE}$ & $\mathrm{T}$ & $\mathrm{df}$ & $\mathrm{P}$ \\
\hline L. argyra & 24.17 & 17.16 & 1.41 & 72 & 0.163 \\
\hline L. sp. & 16.95 & 7.60 & 2.23 & 72 & 0.029 \\
\hline Total area & -0.01 & 0.01 & -0.89 & 72 & 0.374 \\
\hline Cph. width & 1.73 & 7.49 & 0.23 & 72 & 0.817 \\
\hline
\end{tabular}

did not differ between species, but increased with body size in L. argyra, while it decreased with body size in Leucauge sp. (Cph. width vs. L. sp. ${ }^{*}$ Cph. Width, in Number of radii, Table 1). The number of spiral turns was similar in both species and did not correlate with body size in any species, despite the difference in web area.

Similarly, the inclination of the web differed between both species. The inclination was larger in webs of Leucauge sp. $\left(39.7^{\circ} \pm 16.8^{\circ}\right.$; range: $\left.5^{\circ}-85^{\circ}\right)$ than in those of L. $\operatorname{argyra}\left(20.8^{\circ}\right.$ $\pm 11.5^{\circ}$; range: $5^{\circ}-50^{\circ}$ ), but neither the size of spiders nor the total web area had a significant relationship on web inclination (Table 2). On the contrary, the asymmetry of webs did not differ between species, but decreased as total area of webs increased for both species (Table 2); web inclination and spider size did not correlate with web asymmetry.

\section{DISCUSSION}

We found that the total area, as well as the capture, free zone, and hub areas were larger in webs of L. argyra than in those of Leucauge sp., but the number of radii and adhesive spiral turns did not differ between the two species. We also found that the free zone area increases with spider size in both species, but the number of radii increases with body size of $L$. argyra while it decreases with Leucauge sp. body size. Differences in webs between both species are likely the result of the interaction of each species with several biotic and abiotic factors, and decisions organized in a hierarchical manner that spiders make during web construction. For instance, the exploratory behavior prior to web construction presumably provides the spider information on the available space for constructing its web (Eberhard 1972; Hesselberg 2015), but also the final design of the web is affected by fine flexible adjustments the spider makes (e.g., reduction of capture and free zone areas) during the orb web construction (Barrantes \& Eberhard 2012; Eberhard \& Barrantes 2015; Eberhard 2020). For instance, radii construction is independent of the total area of the web, since radii are chronologically constructed prior to the adhesive spiral and the total area is defined by where along a radius the spider decides to
Table 3.--Percentage of capture area, free zone, hub area, number of radii, and number of adhesive spiral turns relative to the total area of Leucauge argyra and Leucauge sp.

\begin{tabular}{lccccr}
\hline & \multicolumn{5}{c}{ L. argyra } \\
\cline { 2 - 6 } & $\begin{array}{c}\text { Capture } \\
\text { area }\end{array}$ & $\begin{array}{c}\text { Free } \\
\text { zone }\end{array}$ & $\begin{array}{c}\text { Hub } \\
\text { area }\end{array}$ & $\begin{array}{c}\text { Number } \\
\text { of radii }\end{array}$ & $\begin{array}{r}\text { Spiral } \\
\text { turns }\end{array}$ \\
\hline Mean & 94.09 & 5.40 & 0.51 & 5.74 & 8.20 \\
SD & 2.16 & 1.96 & $\begin{array}{c}0.29 \\
\text { Leucauge sp. }\end{array}$ & 1.53 & 2.32 \\
Mean & 94.85 & 4.83 & 0.32 & 9.71 & 14.85 \\
SD & 1.47 & 1.38 & 0.13 & 3.19 & 5.07 \\
\hline
\end{tabular}

initiate the first adhesive spiral turn distantly from the hub (Barrantes \& Eberhard 2012; Eberhard \& Barrantes 2015). It is also likely that the design of the web is further modified by silk availability in the spiders' silk glands (Eberhard 1988).

The capture area, free zone, and the hub area are, at least in part, determined by the external limit of the total area, a decision the spider makes when the first turn of the adhesive spiral is set (Ades 1995; Barrantes \& Eberhard 2012; Eberhard \& Barrantes 2015). In both Leucauge species this decision presumably has a similar cascade of effects on the area of other sections of the web, since the proportion of each web section is similar for both species (Table 3). However, the number of radii and adhesive spiral turns show a different pattern. The number of radii and spiral turns are proportionally greater in Leucauge sp. than in L. argyra (Table 3). The main function of radii is to stop prey, and the function of the adhesive spiral is to retain prey; therefore, the probability of stopping, particularly large prey (Eberhard 2014), is expected to increase with the number of radii, and a large number of adhesive spiral turns would increase the probability of retaining prey (Eberhard 1990, 2014; Zschokke 2000; Barrantes et al. 2017). In this case, Leucauge sp. constructs webs with a greater number of radii and adhesive spiral turns, in proportion to the total area of the web (Tables 1, 3); thus, it would be able to stop more large prey and retain them more effectively than L. argyra (Sensenig et al. 2010, 2012; Eberhard 2014). However, data on prey capture is lacking to compare the efficiency of webs between these two species.

To be an effective trap, orb webs need to accomplish three functions (interception, stopping, and retention), but it is likely difficult for a spider to maximize the effectiveness of the three functions in a single web (Eberhard 1990). On the contrary, subtle differences in the orb-web design could reduce, for instance, the interception (e.g., reducing total web area), but favor the stopping function of the web (e.g., increasing number of radii), presumably affecting the type and size of prey captured. In this study, some differences between the webs of the two Leucauge species suggest that each species could optimize some function(s) over others. Leucauge argyra increases the probability of prey interception (larger capture area), but Leucauge sp. seems to optimize stopping and retaining large prey, since webs of this species have more radii and spiral turns concentrated in a smaller web than L. argyra (Eberhard 2014; Barrantes et al. 2017). In both species, the number of radii increases with body size, but with a steeper slope for L. argyra. Differences in these scaling relationships 

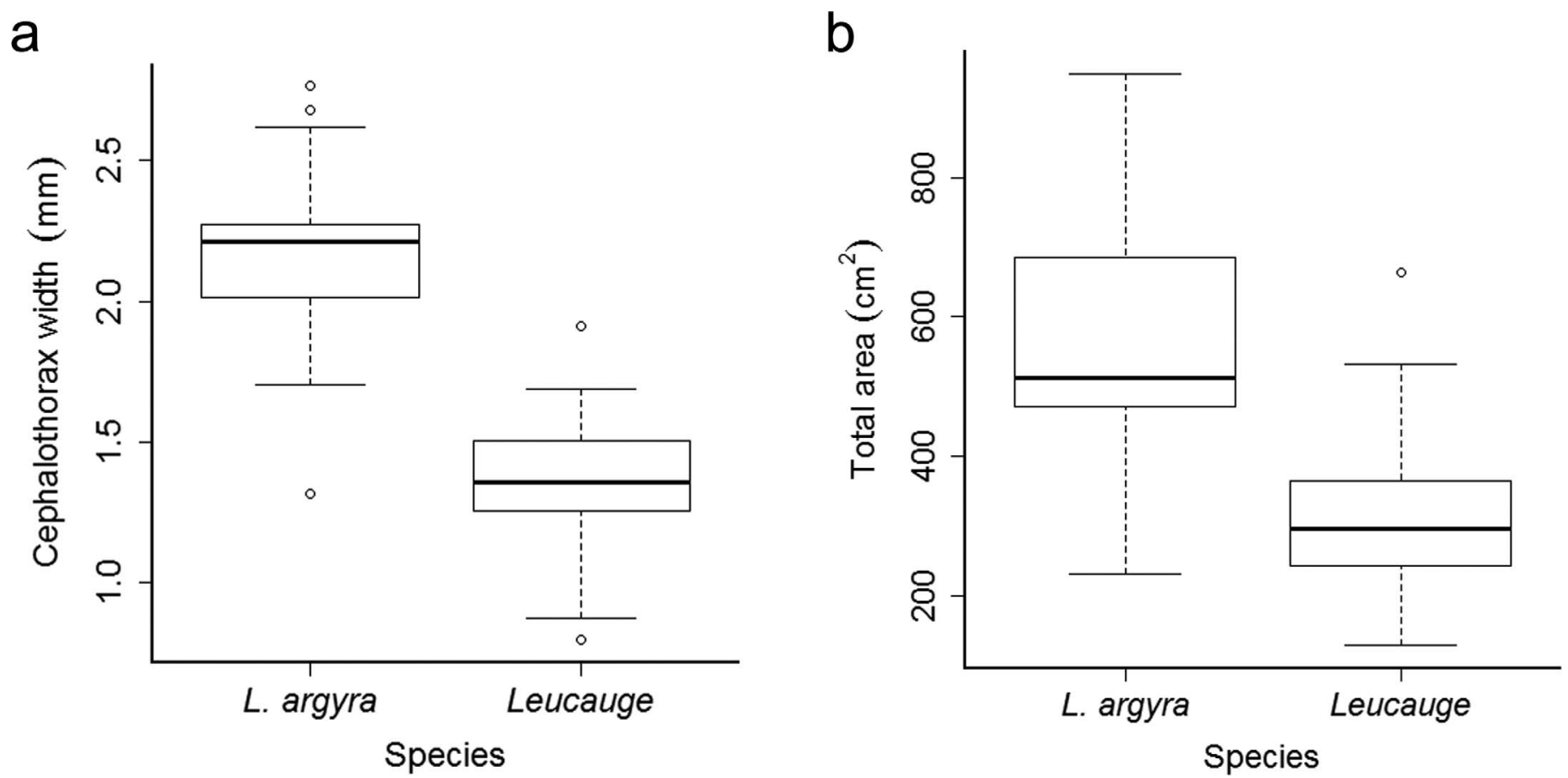

Figure 2.-Cephalothorax width (a) as a proxy of spider size and total area (b) of Leucauge argyra and Leucauge sp.

are likely related with maintaining the effectiveness of intercepting, stopping, and retaining prey of the web of each species.

In addition, webs of Leucauge sp. are in general more inclined, and vary through a larger range of angles than those of L. argyra. Horizontal orb webs are thought to be designed to capture aquatic insects (Kato et al. 2003), as well as falling or jumping prey, while vertical webs are designed to capture primarily fast flying insects (Gregorič et al. 2013), though conclusive data on this issue is lacking (Bishop \& Connolly 1992; Prokop 2005). Thereby, we hypothesize that the webs of Leucauge sp. that range from nearly horizontal $\left(5^{\circ}\right)$ to nearly vertical $\left(85^{\circ}\right)$ are likely capable of intercepting a larger range of prey types than webs of L. argyra, that range from $5^{\circ}$ to $50^{\circ}$, and proportionally more fast flying insects, since some webs are nearly vertical. Fast flying insects accumulate more kinetic energy than either falling, jumping, or slow flying aquatic insects (Eberhard 1986; Bishop \& Connolly 1992; Lin et al. 1995); thus, a large density of radii absorbs this energy more effectively, and a higher concentration of adhesive threads retains prey more effectively in more inclined webs.

Orb webs constructed by nearly all species in the Tetragnathidae and Araneidae families are slanted and asymmetric, with the web section above the hub usually smaller than the lower section. Several non-exclusive factors have been proposed to affect the asymmetry of orb-webs. For instance, in a field study with Metellina mengei (Blackwell, 1869), the web asymmetry increases with the inclination of the web and spider size (Tew \& Hesselberg 2018). In addition, several studies have demonstrated that larger (likely heavier) spiders construct more asymmetric webs (Herberstein \& Heiling 1999; Kuntner et al. 2010). However, in the two Leucauge species included in this study neither the inclination of the web nor the size of the spider correlated with the asymmetry of webs (Table 2); despite the large difference in size, L. argyra did not build more asymmetric webs. Unfortunately, there are no data of weight on the genus Leucauge White, 1841, and in future studies, it would be advantageous to measure spider weight. However, in this particular study, if weight would have a strong effect on asymmetry, webs of Leucauge argyra would be more asymmetric since the estimated weight of this species (based on Penell et al. 2018) was 3.4 times larger than that of Leucauge sp. Other factors, such as the type (e.g., fast vs. slow flying insects) or size of prey captured may also influence the asymmetry of the webs of these two species of Leucauge in the wild. Spiders walk slower upward and evidence indicates that they reduce the area above the hub as the angle of the web increases with the horizontal, affecting web asymmetry (Nakata \& Zschokke 2010; Tew \& Hesselberg 2018).

In both species of Leucauge and in M. mengei (Tew \& Hesselberg 2018), the asymmetry also correlates with the area of the web. In these cases, asymmetry could be related with prey capture efficiency rather than with physical aspects (e.g., web inclination, spider size), since spiders optimize prey capture running faster downwards than upwards against gravity. The available space for web construction and distribution of perches the microhabitat offers are yet other factors that may also affect web asymmetry, since both could influence the area and asymmetry of webs (Blamires et al. 2007).

Niche partitioning, as a direct effect of interspecific competition, is frequently advocated to explain differences in microhabitat use in sympatric spider species (Novak et al. 2010; Nasir et al. 2017). Although the idea of niche differentiation through competition between the two Leucauge species in this study is suggestive, the evidence suggests otherwise. All webs of both species were at the same 
vegetation stratum $(0.20$ to $1.50 \mathrm{~m})$ and, in many cases, webs of both species were constructed side by side. In addition, the small species was more abundant than the larger, opposite to expectations of competitive exclusion. We argue that differences in web design between the two Leucauge species are more likely attributed to species-specific behavioral adjustments to similar environmental conditions rather than to the effect of competition, as Wise (1993) demonstrated with carefully conducted field experiments.

Summarizing, the total area of the web and that of the different sections (e.g., hub, capture area) were larger in webs of L. argyra than in Leucauge sp., but webs of both species had a similar number of radii and sticky spiral turns, despite the differences in total web area. In addition, the range of inclination in webs of Leucauge sp. (from nearly vertical to nearly horizontal) was larger than that of L. argyra. Differences in the webs of these two sympatric congeneric species suggest that each species optimizes different aspects of the web. Although the prey interception efficacy of orb webs depends on a set of conditions which involve prey size and type, insect wing span, web light reflectance, and wind speed, the size of the orb is an important variable (Craig 2003; Yuen \& Bonebrake 2017). In addition, several authors have hypothesized that prey stopping increases with radii density and their retention with spiral turns density (Eberhard 2014; Blackledge et al. 2011). Hence, we speculate that the large webs of L. argyra could increase the probability of prey interception without sacrificing prey stopping, since number of radii increases with spider size and web area (Barrantes \& Eberhard 2012; Eberhard 2014); while webs of Leucauge sp. could increase the probability of stopping and retaining large prey as its webs had a larger density of radii and adhesive spiral turns. Contrary to our expectations and despite the large differences in size between both species, body size did not affect the asymmetry of the web. These two sympatric species produce webs with different designs that could optimize different aspects of their webs: L. argyra optimizes prey interception, and Leucauge sp. optimizes prey stopping and retention, but field data are needed to test the effect of different orb-web designs on prey capture.

\section{ACKNOWLEDGMENTS}

We would like to thank two anonymous reviewers for their exhaustive and detailed revision of the manuscript that largely improve this paper, and the Vicerrectoría de Investigación, Universidad de Costa Rica (project C0-252) for providing financial support (GB). Data for this manuscript was obtained by AVG in the Field Biology course, Universidad de Costa Rica.

\section{LITERATURE CITED}

Ades C. 1995. A construcao da teia geométrica enquanto instinto: primeira parte de um argumento. Psicologia USP 6:145-172.

Aisenberg A, Barrantes G. 2011. Sexual behavior, cannibalism, and mating plugs as sticky traps in the orb weaver spider Leucauge argyra (Tetragnathidae). Naturwissenschaften 98:605-613. https:// doi.org/10.1007/s00114-011-0807-y

Barrantes G. 2015. Effect of body size and maternal care on clutch size and egg size in theridioids. Boletín de la Sociedad Zoológica del Uruguay 24:83-92.
Barrantes G, Eberhard WG. 2012. Extreme behavioral adjustments by an orb-web spider: the paradox of adaptive adjustments to unnaturally restricted spaces. Ethology 118:438-449. https://doi. org/10.1111/j.1439-0310.2012.02029.x

Barrantes G, Sánchez-Quirós C, Aisenberg A, Leitch K, Eberhard WG. 2015. Loss of cheliceral clasping Leucauge sp. (Araneae, Tetragnathidae). Arachnology 16:281-286. https://doi.org/10. 13156/arac.2015.16.8.281

Barrantes G, Triana E, Sánchez-Quirós C. 2017. Functional changes in web design along the ontogeny of two orb-weavers. Journal of Arachnology 45:152-159. https://doi.org/10.1636/JoA-S-16-026.1

Bishop L, Connolly SR. 1992. Web orientation, thermoregulation, and prey capture efficiency in a tropical forest spider. Journal of Arachnology 20:173-178.

Blackledge TA, Kuntner M, Agnarsson I. 2011. The form and function of spider orb webs: evolution from silk to ecosystems. Insect Physiology 41:175-262.

Blamires SJ, Thompson MB, Hochuli DF. 2007. Habitat selection and web plasticity by the orb spider Argiope keyserlingi (Argiopidae): Do they compromise foraging success for predator avoidance? Austral Ecology 32:551-563. https://doi.org/10.1111/j.14429993.2007.01727.x

Boutry C, Blamires SJ. 2013. Plasticity in spider webs and silk: an overview of current evidence. Pp. 1-46. In Spiders: Morphology, Behavior and Geographic Distribution. (M. Santerre, ed.). Nova Science Publishers, New York.

Briceño RD, Eberhard WG. 2011. The hub as a launching platform: rapid movements of the spider Leucauge mariana (Araneae: Tetragnathidae) as it turns to attack prey. Journal of Arachnology 39:102-112. https://doi.org/10.1636/Hi10-76.1

Collias NE, Collias EC. 1984. Nest Building and Bird Behavior. Princeton University Press, Princeton, New Jersey.

Craig CL. 2003. Spider Webs and Silk. Tracing Evolution from Molecules to Genes to Phenotypes. Oxford University Press, Oxford, New York.

Eberhard WG. 1972. The web of Uloborus diversus (Araneae: Uloboridae). Journal of Zoology 166:417-465. https://doi.org/10. 1111/j.1469-7998.1972.tb04968.x

Eberhard WG. 1986. Effects of orb-web geometry on prey interception and retention. Pp. 70-100. In Spiders: Webs, Behaviour and Evolution (W.A. Shear, ed.). Stanford University Press, California.

Eberhard WG. 1988. Behavioral flexibility in orb web construction: effects of supplies in different silk glands and spider size and weight. Journal of Arachnology 16:295-302. https://www.jstor.org/ stable/3705916

Eberhard WG. 1990. Function and phylogeny of spider webs. Annual Review in Ecology and Systematics 21:341-372. https://doi.org/10. 1146/annurev.es.21.110190.002013

Eberhard WG. 2014. A new view of orb webs: multiple trap designs in a single structure. Biological Journal of the Linnean Society 111:437-449. https://doi.org/10.1111/bij.12207

Eberhard WG. 2020: Spider Webs: Behavior, Function, and Evolution. University of Chicago Press, Ill.

Eberhard WG, Barrantes G. 2015. Cues guiding uloborid construction behavior support orb web monophyly. Journal of Arachnology 43:371-387. https://doi.org/ 10.1636/arac-43-03-371-387

Gregorič M, Kiesbüy HC, Quiñones-Lebrón SG, Rozman A, Agnarsson I, Kuntner M. 2013. Optimal foraging, not biogenetic law, predicts spider orb web allometry. Naturwissenschaften 100:263-268. https://doi.org/10.1007/s00114-013-1015-8

Hansell M. 2005. Animal Architecture. Oxford University Press, Oxford, UK.

Heiling AM, Herberstein ME. 1998. The web of Nuctenea sclopetaria (Araneae, Araneidae): relationship between body size and web design. Journal of Arachnology 4:115-124. 
Heiling AM, Herberstein ME. 2000. Interpretations of orb-web variability: a review of past and current ideas. Ekológia Bratislava 19:97-106.

Herberstein ME, Heiling AM. 1999. Asymmetry in spider orb webs: a result of physical constraints? Animal Behaviour 58:1241-1246. https://doi.org/10.1006/anbe.1999.1255

Herberstein M, Tso IM. 2011. Spider webs: evolution diversity and plasticity. Pp. 57-98. In Spiders Behaviour. Flexibility and Versatility (Herberstein M, ed.). Cambridge University Press, UK.

Hesselberg T. 2010. Ontogenetic changes in web design in two orbweb spiders. Ethology 116:535-545. https://doi.org/10.1111/j.14390310.2010.01760.x

Hesselberg T. 2013. Web-building flexibility differs in two spatially constrained orb spiders. Journal of Insect Behavior 26:283-303. https://doi.org/10.1007/s10905-012-9335-7

Hesselberg T. 2015. Exploration behaviour and behavioural flexibility in orb-web spiders: a review. Current Zoology 61:313-327. https:// doi.org/10.1093/czoolo/61.2.313

Janetos AC. 1986. Web-site selection: are we asking the right questions? Pp. 9-22. In Spiders: Webs, Behavior, and Evolution (Shear WA, ed.). Stanford University Press, California.

Kato C, Iwata T, Nakano S, Kishi D. 2003. Dynamics of aquatic insect flux affects distribution of riparian web-building spiders. Oikos 103:113-120. https://doi.org/10.1034/j.1600-0706.2003. 12477.x

Kuntner M, Kralj-Fišer S, Gregorič M. 2010. Ladder webs in orbweb spiders: ontogenetic and evolutionary patterns in Nephilidae. Biological Journal of the Linnean Society 99:849-866. https://doi. org/10.1111/j.1095-8312.2010.01414.x

Lin LH, Edmonds DT, Vollrath F. 1995. Structural engineering of an orb-spider's web. Nature 373:146-148. https://doi.org/10.1038/ $373146 \mathrm{a} 0$

Nakata K. 2010. Does ontogenetic change in orb web asymmetry reflect biogenetic law? Naturwissenschaften 97:1029-1032. https:// doi.org/10.1007/s00114-010-0719-2

Nakata K, Zschokke S. 2010. Upside-down spiders build upsidedown orb webs: web asymmetry, spider orientation and running speed in Cyclosa. Proceedings of the Royal Society B 277:30193025. https://doi.org/10.1098/rspb.2010.0729

Nasir DM, Goh TG, Bakri A, Rahim F, Mohamed Z, Yusoff NR. 2017. Web characteristics determine niche partitioning for orb-web spiders (Araneae, Tetragnathidae) in Malaysia. Oriental Insects, https://doi.org/10.1080/00305316.2017.1282385

Novak T, Tkave T, Kuntner M, Arnett AE, Delakorda SL, Perc M et al. 2010. Niche partitioning in orbweaving spiders Meta menardi and Metellina merianae (Tetragnathidae). Acta Oecologica 36:522529. https://doi.org/10.1016/j.actao.2010.07.005

Penell A, Raub F, Höfer H. 2018. Estimating biomass from body size of European spiders based on regression models. Journal of Arachnology 46:413-419. https://doi.org/10.1636/JoA-S-17-044.1

Prokop P. 2005. Web inclination alters foraging success of a nocturnal predator. Italian Journal of Zoology 72:249-252. https://doi.org/10.1080/11250000509356679

Rasband WS. 2016. ImageJ, U. S. National Institutes of Health, Bethesda, Maryland, USA. 1997-2016. http://imagej.nih.gov/ij/

Sandoval CP. 1994. Plasticity in web design in the spider Parawixia bistriata: a response to variable prey type. Functional Ecology 8:701-707. https://doi.org/10.2307/2390229

Sensenig A, Agnarsson I, Blackledge TA. 2010. Behavioural and biomaterial coevolution in spider orb webs. Journal of Evolutionary Biology 23:1839-1856. https://doi.org/10.1111/j.1420-9101.2010. 02048.x

Sensenig AT, Lorentz KA, Kelly SP, Blackledge TA. 2012. Spider orb webs rely on radial threads to absorb prey kinetic energy. Journal of the Royal Society Interface 9:1880-1891. https://doi.org/10. 1098/rsif.2011.0851

Solano, J. \& R. Villalobos. 2001. Aspectos fisiográficos aplicados a un bosquejo de regionalización geográfico climático de Costa Rica. Tópicos Meteorológicos y Oceanográficos 8:26-39.

Tew N, Hesselberg T. 2018. Web asymmetry in the tetragnathid orb spider Metellina mengei (Blackwell, 1869) is determined by web inclination and web size. Journal of Arachnology 46:370-372. http://doi.org/10.1636/JOA-S-17-065.1

Vollrath F. 1992. Spider webs and silk. Scientific American 26:70-76. Vollrath F. 1998. Untangling the spider's web. Trends in Ecology and Evolution 3:331-335. https://doi.org/10.1016/0169-5347(88)90089-4

Wagenmakers EJ, Farrell S. 2004. AIC model selection using Akaike weights. Psychonomic Bulletin \& Review 11:192-196. https://doi. org/10.3758/BF03206482

West-Eberhard MJ. 2003. Developmental Plasticity and Evolution. Oxford University Press, New York.

Wise DH. 1993. Spiders in Ecological Webs. Cambridge University Press, New York.

Witt PN. 1965. Do we live in the best of all worlds? Spider webs suggest an answer. Perspectives in Biology and Medicine 8:475-487. https://doi.org/10.1353/pbm.1965.0056

Yuen SW, Bonebrake TC. 2017. Artificial night light alters nocturnal prey interception outcomes for morphologically variable spiders. PeerJ 5:e4070. http://doi.org/10.7717/peerj.4070

Zschokke S. 2000. Form and function of the orb-web. Pp. 99-106. In Proceedings of the 19th European Colloquium of Arachnology (S. Toft \& N. Scharff, ed.). Aarhus University Press, Denmark.

Zschokke S. 2011. Spiral and web asymmetry in the orb webs of Araneus diadematus (Araneae: Araneidae). Journal of Arachnology 39:358-362. https://doi.org/10.1636/CB10-61.1

Zuur AF, Saveliev AA, Ieno EN. 2012. Zero Inflated Models and Generalized Linear Mixed Models with R. Highland Statistics Ltd., Newburgh, UK.

Manuscript received 11 October 2019, revised 16 December 2020. 